\title{
Democracia y conflicto: la democracia como movimiento histórico
}

\author{
Beatriz Silva Pinochet \\ Universidad de Barcelona, Barcelona, España. \\ Email: beatrizsilvapinochet@gmail.com
}

\begin{abstract}
Resumen $^{\mathbf{1}}$ : El presente artículo tiene el objetivo de comprender la democracia y la democratización como un proceso conflictivo, el cual requiere de una mirada histórica y situada en los actores para poder ser analizado. Se postula que dicha mirada se encuentra actualmente ausente en gran parte de los análisis provenientes de la sociología, la ciencia política y la economía, los que se revisan brevemente, considerando sus aportes y falencias, así como algunos de los presupuestos metodológicos y epistemológicos asociados a la problemática planteada. Finalmente, se intenta realizar un aporte aeste análisis, tratando de entender la democracia como un movimiento histórico, a través del concepto de "modernidad política”, así como de las herramientas teóricas que nos entregan, desde la filosofía/sociología y la historia, dos autores como son Axel Honneth y su "lucha por el reconocimiento" y E.P. Thompson y su análisis sobre “economía moral de la multitud”.

Palabras Clave: Democracia, democratización, conflicto, economía moral de la multitud, lucha por el reconocimiento
\end{abstract}

\section{Democracy and conflict: democracy as a historicalmovement}

Abstract: Thisarticle has theobjective to understand democracy and democratization as a conflictive process that requires a historical and agency-based approach to be analyzed. It states that this perspective is currently missing in significant part of sociological, political science and economican alysis. Some of these analyses are briefly reviewed in the text, along with considering its gaps and contributions, and some of its methodological and epistemological as sumptions on the topic. Finally, thearticle intends to make a contribution to the analysis, by trying to understand democracy as a historical movement, exploring the use of the concept of "political modernity", and some of the theoretical tools that twoi mportant authors have given us. Those are, Axel Honneth with his analysis on the "struggle for recognition", and E.P. Thompson with hishistorical approach and his concept of "moral economy of multitude".

Keywords: Democracy, democratization, conflict, moral economy of multitude, struggle for recognition

\section{Democracia e conflito: a democracia como movimento histórico}

Resumo: O presente artigo tem o objetivo decompreender a democracia e a democratização como um processo conflitivo, o qual requer de um olhar histórico e situado nos atores para poder ser analisado. Se postula que esse olhar encontra-se 
atualmente ausente emgrandeparte das análises provenientes dasociologia, a ciência política e a economia, os que se revisambrevemente, considerando seus aportes e falências, assimcomo alguns dos pressupostos metodológicos eepistemológicos associados àproblemática planteada. Finalmente, se procura realizar umaporte a esta análise, tentando entender a democracia como um movimento histórico, através do conceito de "modernidade política", assimcomo das ferramentas teóricas que nos entregam, desde a filosofia/sociologia e a historia, dois autores como sãoAxel Honnethe sua"lutapeloreconhecimento" e E.P. Thompson e sua análise sobre a “economia moral da multidão.

Palavras Chaves: Democracia,democratização,conflito, economia moral da multidão, luta pelo reconhecimento

\section{Introducción}

Distintas corrientes teóricas propias de las ciencias sociales han desarrollado, en las últimas décadas, un análisis lineal de la sociedad y la democracia, en la que el conflicto ha venido a ser presentado como expresión de una enfermedad del "organismo social" o bien, se ha entendido como superado con la desaparición de las oposiciones políticas (democracia de consensos). Esto ha derivado hacia la limitación del debate político, a la tecnocratización de la política y a la subvaloración de cualquier discurso de transformación profunda de la realidad.

No obstante, si realizamos una revisión del análisis sobre conflicto político en perspectiva histórica, es posible observar que los períodos de conflicto social y político han sido esenciales para llevar adelante los procesos de cambio que han dado lugar a esquemas sociales más democráticos (Rifo, 2016; Wagner, 1995, p. 13).

De este modo, la democratización, que desde una perspectiva lineal aparece como natural o bien se presenta como un proceso de buena voluntad y aprendizaje dialogante de los miembros de una comunidad política, ha sido más bien -la mayor parte de las veces-, consecuencia de una serie de enfrentamientos sociales, y principalmente de largas luchas por el reconocimiento (Honneth, 1997).

En este sentido, el presente texto tiene como objetivo realizar un aporte al análisis del conflicto democratizador. Para esto se realizará en primera instancia, una breve revisión acerca de cómo se ha abordado y qué significado se le ha dado al conflicto político para la teoría política y las ciencias sociales, para después comprender cuáles son los ejes que han marcado el análisis sobre el conflicto democratizador limitando, sobre todo en el actual período, la posibilidad tanto teórica, como práctica, de plantear en una profundización democrática, que supere el esquema -implícitamente - normativo, de la democracia liberal. En esta línea, como segundo punto se hará una breve propuesta conceptual que permita avanzar hacia un análisis dinámico sobre democracia y democratización, para, finalmente, abordar 
ciertas herramientas epistemológicas que nos entregan los trabajos del historiador inglés E.P. Thompson y del filósofo y sociólogo alemán, Axel Honneth. A través de sus aportes, intentaremos comprender la democratización insertándole un nivel de complejidad que no constriña sus causas a una sola variable, ni la disocie del contexto social, histórico y conflictivo en la que éstase produce, la que permite comprender que la democracia es un proceso en construcción y no un sistema de reglas estático, ni que se acrecienta automáticamente, sino que se reconfigura en el debate.

\section{Breve aproximación a las teorías del conflicto: desde la teoría política a las ciencias sociales}

El análisis sobre la utilidad y la incidencia del conflicto ha estado presente desde siempre en la teoría política. Éste existía ya en la antigua Grecia, simbolizado en la disputa entre los sofistas y Platón, donde la retórica era criticada por este filósofo dada la negación que esta práctica implicaba de un orden natural indiscutible (Serrano Gómez, 1997, p. 45). El conflicto y el debate, por tanto, no podían interferir con aquella verdad esencial, por lo que el conflicto era necesariamente dañino.

Para Aristóteles por su parte, la “discordia” aparecía y era alentada por "hombres malos" orientados hacia sus propios intereses (Domenèch, 2003, p. 45). No obstante, la etimología del término malo en griego (Phaûlos), permite a Antoni Domènech interpretar que estos "hombres malos", no eran otros sino los pertenecientes al demos(Domenèch, 2003, p. 48). El conflicto para Aristóteles, iría asociado así a la intromisión de los pobres libres en la polis, es decir, el conflicto era -malamente- intrínseco a la democracia.

El resurgimiento de laRes-publica y la sociedad civil en algunos pequeños estados italianos hará reflexionar también a Maquiavelo sobre el conflicto (A. Hirschman, 1994; Serrano Gómez, 1997:45). En este caso, sin embargo, su enfoque irá hacia entender el conflicto como inherente y constructivo para el bien común, el que surgiría del disenso, de la deliberación y del posterior acuerdo. Esta visión, no obstante, siempre habría sido mantenida por el republicanismo clásico, el que habría buscado establecer sistemas políticos orientados a "revelar las escisiones principales y fundamentales de la sociedad” (Domenèch, 2003, p. 70).

Con el surgimiento del liberalismo a fines del siglo XIX, por otro lado, el conflicto -concebido por Hobbes bajo la idea de "estado de naturaleza”- aparecerá y reaparecerá con la pérdida de legitimidad de un orden social (Serrano Gómez, 1997, p.50). Para Hobbes, el conflicto tendrá el atributo de provocar miedo y tendencia al consenso en pro de un orden social estable. En este sentido, el resultado positivo del conflicto, que para Maquiavelo se fundará en la participación activa de los ciudadanos, para Hobbes derivará en el "efecto positivo" del temor y posterior deseo de delegación de la responsabilidad política (Velasco, 2002, p. 9). 
Ya en plena ilustración, la dialécticahegeliana, realizarán un aporte hacia una visión dinámica del conflicto y de la propia historia, lo que permitirá otorgarle un “fin” al conflicto, atribuyéndole un sentido o un espíritu que lo guía (Hegel, 2003). No obstante, para el joven Marx, inspirado y criticando a Hegel, la dialéctica no se fundará en la razón, ni en la institucionalidad, sino en las relaciones productivas que sostienen a las primeras. De este modo, para Marx el conflicto estará latente, haciéndose evidente con la agudización de las contradicciones de clase.

Entrando ya al terreno de la Sociología, los grandes cambios sociales producidos a finales del siglo XIX y principios del XX potenciarán la aparición de la ciencia social, y -con un énfasis en el conflicto-, también de la disciplina sociológica(Collins, 1996, p.150; Dahrendorf, 1958, p.170; Serrano Gómez, 1997, p.55). No obstante, el análisis específico sobre el conflicto iniciado en 1908 por George Simmel ${ }^{2}$ será olvidado después de la primera guerra mundial. El análisis sobre el conflicto será retomado tiempo más tarde en Estados Unidos, desde una visión funcionalista (A. Hirschman, 1994, p. 208).

El funcionalismo, como un ejemplo de una sociología orientada a deshistorizar los procesos sociales, será un reflejo del rechazo al conflicto y del énfasis en la cohesión social, viéndose afectado por el contexto post primera guerra mundial. Esta corrriente teórica entenderá el conflicto como algo "no sano” y no inherente a lo social, que entorpecería una dinámica que tiende hacia el equilibrio entre sus partes (Dahrendorf, 1966:113). Desde otras perspectivas, el conflicto también sería una evidencia de "tensiones” en diferentes niveles de la estructura social (Smelser, 1995). No obstante, mantendría su carácter “no sano” y propio de una disfuncionalidad.

Los grandes conflictos que traerá la segunda guerra mundial, influenciarán muchos análisis que intentarán comprender la profundización democrática al interior de las sociedades no soviéticas ${ }^{3}$. En esta línea, Helmut Dubiel reflexionará acerca de cómo las sociedades democráticas se mantendrían unidas gracias al conflicto “cultivado”, el que caracteriza un tipo de conflicto social que se orienta por el autocontrol y el interés por mantener las reglas y leyes, pero también las actitudes y la cultura que sancionan los excesos del conflicto (Dubiel, 1998, p. 211). Desde esta perspectiva, la idea de conflicto como diferencia y no como supresión, sería la que lograría construir una sensación de espacio social compartido (Dubiel, 1998, p. 211). De este modo, y así como lo denomina Marcel Gauchet, el conflicto plantearía una paradoja: esta es de un “milagro democrático” (A. Hirschman, 1994, p. 206).

A partir de esta reflexión, no obstante, el filósofo Albert Hirschman, atribuirá dicha característica democratizadora del conflicto -de manera exclusiva- a la democracia liberal, esto dado que el orden liberal-democrático sería el único que produciría conflictos de "más y menos”, es decir, de negociación o “conflictos divisibles”. Para Helmut Dubiel, sin embargo, los conflictos "indivisibles” estarían presentes en cualquier sociedad y se desarrollarían en torno a características adscriptivas(Dubiel, 1998, p. 212). En 
este sentido, y como reflexiona Axel Honneth (Honneth, 1997), el conflicto democratizador se asociaría a una lucha por el reconocimiento y por tanto, podría atribuirse a cualquier conflicto identitario, que no excluye a los conflictos "de más y menos", ni tampoco a los de clase, pues estos últimos también se fundan en una identidad. Según Dubiel señala "If one were to examine origins, dynamics, and political careers of social movements throughout history, one would conclude that ideas without interests quickly become frivolous” (Dubiel, 1998:215); y a esto podríamos agregar, que los intereses sin identidad tampoco generan movimiento. Desde esta perspectiva, el conflicto democratizador referiría tanto a movimientos identitarios, como a aquellos que se han entendido como exclusivamente asociados al interés colectivo o de clase.

Desde la sociología, por otro lado, y en oposición al foco puesto por parte del funcionalismo en comprender la cohesión social (Dahrendorf, 1958, p. 174) y tratando también de incorporar y de “superar” el análisis marxista, Ralph Dahrendorf se abocará a comprender el conflicto situado en una estructura de dominación, así como posiciones que representan intereses en disputa. Para Dahrendorf, el conflicto sería "un elemento vital de las sociedades”, aunque, para este autor, no sería lo único que provoca cambio (Dahrendorf, 1966, p. 120).

Durante este período otros sociólogos buscarán realizar nuevos análisis que profundizarán en los aspectos que inciden en conflicto, atribuyéndolo a distintas causas (conductuales, ideológicas y relacionales) (Tilly, 2007:5). También se desarrollarán análisis más estructurales que incorporarán diferentes variables para la comprensión de este fenómeno, algunos de los cuales, sin embargo, terminarán atribuyendo a la estructura total capacidad de reproducción del orden (y desviación del conflicto) y asumirán implícitamente, por ende, la imposibilidad del cambio democratizador (Callinicos, 2009; Thompson, 1981; Wagner, 1995). Este énfasis teórico en la sobreestructuración, a la par del desencanto que aportarán los discursos postmodernos, traerá consigo un relativismo epistemológico, que permeará también la posibilidad de profundizar la democracia, diluyendo la movilización colectiva y limitando el análisis académico a lo "humanamente posible".

Por otro lado, la importancia del conflicto asociado a las identidades se irá presentando en mayor medida después de la ola de movilización que sobrevendrá a fines de la década del '70, la que dará lugar a al análisis sobre “nuevos movimientos sociales”. Este análisis incorporará -entre otros aspectos- una forma de entender el conflicto y la movilización social, a través de la acción de personas no necesariamente situadas en la misma posición de clase (como se había hecho hasta la fecha), sino relacionadas por intereses no materiales o identidades adscriptivas comunes. El análisis sobre “movimientos” pondrá el foco en la dinámica propia de la acción colectiva, separándose también del análisis funcionalista que los atribuía generalmente a prácticas no conscientes e irracionales. Desde la perspectiva de movimientos sociales, entonces, se revisará su recurrencia (ciclos de movilización), sus discursos, el “esquema de oportunidades políticas” que gatilla 
su aparición, los repertorios, etc. También se analizarán las dinámicas organizacionales, las redes, la negociación y otros aspectos que, en algunos casos, dejaran de lado el análisis estructural y el factor democratizador de estas formas de conflicto.

Una corriente de la sociología que se preocupará predominantemente del conflicto democratizador a nivel estructural será la sociología histórica, la que continuará la línea que iniciara Max Weber a través de su idea de una disciplina que contemplara la historia, la economía y la sociología, pero también por el joven Marx con su énfasis histórico inicial (Collins, 1996, p.87; Wagner, 2001, p. 26). La sociología histórica intentará comprender cómo han surgido y se han desarrollado los diferentes conflictos que han dado origen a distintos sistemas políticos y económicos a nivel mundial, manteniendo la línea de entender los grandes estructuras, los procesos amplios y las comparaciones enormes” (Tilly, 1991). De este modo, se cruzará también -aunque más limitado en estos casos- con el análisis comparativo, la transitología y la “democratización” más cercanos a la ciencia política. Estos últimos tipos de análisis, no obstante, apuntarán generalmente a evaluar las dinámicas de los “sistemas democráticos,” más que las grandes transformaciones políticas.

El sociólogo Barrington Moore es quizás uno de los exponentes más importantes cuando se habla de sociología histórica. Éste intentará responder cuáles son "los orígenes sociales de la dictadura y la democracia” (Moore, 2002). Centrándose en el análisis de distintos territorios que alcanzaron un sistema democrático o bien uno “totalitario”, en base a la movilización y poder relativo de las diferentes fuerzas sociales en disputa, Moore revisará los casos de Francia, Inglaterra, Estados Unidos, India, China y Rusia, entre otros. Desde su definición, las movilizaciones que llevaron a la "democracia” irán dirigidas a conseguir tres objetivos: eliminar a los gobernantes arbitrarios, sustituir los regímenes arbitrarios por otros justos y racionales y lograr que el pueblo participe en la construcción de los regímenes (Moore, 2002, p. 507). El problema que presenta el análisis de Moore, sin embargo, se encuentra en que no ahonda en la definición de democracia que implícitamente asume. En este sentido, califica los movimientos o conflictos que no derivaron en un sistema democrático, como necesariamente "no democratizadores" Sin embargo, si miramos más detenidamente su definición respecto al objetivo democratizador de aquellos que sí consiguieron un llegar a la democracia Moore no aclara qué sería lo que estos establecen como justo y racional o cuál sería el “pueblo” al cual estos quieren integrar, mientras al mismo tiempo atribuye un "efecto democratizador”, solo a los grupos que protegen la libertad individual y el derecho de propiedad.

Desde esa perspectiva, el análisis de Moore pierde contenido histórico, al no contemplar un análisis dinámico sobre democratización y sobre el concepto de democracia que utilizan las propias fuerzas en disputa. Cabe recordar que, así como la democracia se entendió originariamente como la irrupción del “demos”, o la participación de los pobres libres en la polis (Domenèch, 2003), los movimientos revolucionarios en Francia, Rusia, In- 
glaterra y Estados Unidos, estarán conformados también por sectores que incluirán una demanda por mayor igualdad (inclusión del demos), demanda que irá asociada, por lo general, a la de reconfiguración de la propiedad, consideración de formas de propiedad que permitiesen a los pobres ser incluidos en la polis o formas de decisión más participativas. Los movimientos sociales de levellers, los marianistas(Gauthier, 2007) o la forma de soviets al inicio de la Revolución Rusa serán ejemplos de este tipo de demanda y no puede excluírseles sin más del movimiento democratizador-. Por otro lado, para Moore, el componente anticapitalista de algunos de estos grupos será necesariamente anti-moderno y por ende, no democrático ${ }^{4}$, cayendo en un común error respecto de asociar el capitalismo de manera directa a la democracia.

Una mirada que relativiza este último error, haciendo un análisis sobre el conflicto democratizador en perspectiva histórica la entregará Göran Therborn, enfatizando en el proceso vivido por algunos países de Europa durante el siglo XX. Profundizando el concepto de democracia Therborn indicará que a la fecha en que escribe (1977) solo serán unos pocos países de la OCDE los que habían logrado la "democracia burguesa" 5 contemplando elecciones abiertas sin excepción de género, raza u otras limitaciones (como podía ser la renta). Por otro lado, Therborn señalará que los distintos niveles de democratización alcanzados por los países en Europa durante el siglo XX, se asociarían a la contingencia militar del periodo entre guerras o bien, al objetivo de mantener la unidad nacional en momentos de grandes movilizaciones internas. Estos factores serán los que presionarán hacia la extensión del voto a toda la población de los países de la OCDE (solo con algunas excepciones más tardías) (Therborn, 1977a). A partir de esto, Therborn concluirá que no serían las movilizaciones nacionales por sí solas las que han logrado presionar hacia la democratización (Therborn, 1977ª p. 23), sino también el contexto geopolítico internacional el que será tanto un aliciente como una limitante para profundizar la democracia burguesa. Al mismo tiempo, para Therborn reconoce que, si bien el capitalismo no produce genera un sistema democrático, sí traería consigo una serie de cambios que hacen posible la organización de las clases trabajadoras y los subsecuentes movimientos sociales, que, "han jugado un rol vital en la lucha por la democracia” (Therborn, 1977a:p. 29, traducción propia).

Un análisis más actual es el de Samuel P. Huntington, quien distingue entre distintas formas de capitalismo, las que conllevan diferentes formas de democracia. De este modo, el capitalismo industrial, a diferencia del extractivo generaría una transformación económica y social más profunda, así como un entramado social más complejo y valores "que estimulan la democratización” (Huntington, 1994, p.70). Según el análisis de Huntington, la década de los '70 habría traído una tercera ola democratizadora, la que estaría asociada al crecimiento de la clase media y el crecimiento del PIB (Huntington, 1994, p.75).

No obstante, esta nueva relación directa entre índices económicos o variables estructurales como precondiciones para que se produzca el cam- 
bio democratizador es criticado por el sociólogo y cientista político DankwartRustow(Rustow, 1970). Rustow busca así superar una visión genética-funcionalista, propia de la sociología estadounidense de la postguerra y latinoamericana a través de los trabajos de Gino Germani y MedinaEcheverría (Aguilar, 2005, p. 11), la que establece criterios y características iniciales para el surgimiento y/o estabilidad de la democracia, o confundiendo correlación con causación, lo que mezcla las causas para la generación de la democracia con los requisitos que pueden ayudar en su estabilidad y/ o resultados (Rustow, 1970,p. 341). En base a esto Rustow propone un modelo de análisis del conflicto democratizador más “dinámico", en el que que no establezcan relaciones univocas entre supuestas causas y consecuencias de la democracia o entre estructura y súper estructura, sino que permitan un análisis “circular” (Rustow, 1970,p. 351). Si bien para Rustow, la emergencia de la democracia estaría relacionada con algún tipo de conflicto importante, como puede ser el relacionado con diferencias de clase, el tipo de conflicto y las fuerzas involucradas pueden cambiar caso a caso e incluso durante el tiempo. (Rustow, 1970,p. 363), por lo que el análisis histórico debe ser un componente importante para abordar la comprensión de los procesos de democratización: "History (...) is far tooimportant a topic to be leftjust to historians” (Rustow, 1970, p. 347).

Finalmente y en un contexto de crisis del capitalismo en la década del '70 y en conjunto con el fin de las posibilidades democratizadoras-no capitalistas en América Latina, la teoría democrática quedará por largo tiempo en manos -principalmente- de economistas y cientistas políticos. Esta situación producirá la limitación del análisis sobre democracia y democratización, estableciéndose nuevamente una relación implícita entre capitalismo y democracia, así como también entre conflicto e interés egoísta, a partir de lo cual toda demanda será interpretada como necesariamente individualista y racional instrumental. Desde esta perspectiva, se ha limitado -incluso epistemológicamente- la demanda por mayor igualdad y participación que históricamente han presentado los movimientos democratizadores, mientras al mismo tiempo el conflicto político se entiende como artificial y dañino.

Uno de los más más reconocidos respecto de cómo entender la democracia o más bien la "poliarquía” es el estadounidense Robert Dahl . Este autor, en su libro de 1989, "La Democracia y sus Críticos", atribuye los problemas de este sistema a una confusión de escalas y a una idealización sobre la democracia. Dahl señala que, dado este cambio de escala desde la polis a los grandes territorios, resulta imposible evaluar las actuales democracias bajo los parámetros que caracterizaban a las democracias de menor escala; no obstante, la visión clásica de la democracia entraría permanentemente en conflicto con la de democracia en la escala actual, o más específicamente, con la de poliarquía, término con el que Dahl -ya en el año 1971-, buscaba definir el modelo político democrático realmente existente (Dahl, 1992, p.262).

Sin embargo, en la actualidad, según señala Samuel P. Huntington esta definición "procedimental” de democracia o "poliarquía” entendida 
como competencia, representatividad y elecciones periódicas, "triunfa” frente a otras visiones más sustantivas (Huntington, 1994:20). Este cierre epistemológico e histórico surge a partir de la irrupción de diversas dictaduras en América Latina, que ha derivado en que estudios más recientes sobre conflicto y democratización, se orienten más a entender o definir el proceso de reinstalación, más que de definición, aparición o profundización de un sistema democrático. Estos estudios han sido desarrollados especialmente desde la corriente de análisis comparativos, con distintas escuelas que aplican diferentes perspectivas, entre ellas las que abordan el análisis de las transiciones con el foco puesto en las élites -el que sería predominante sobre todo desde los análisis realizados por O’Donnell y Schmitter(Collier \& Mahoney, 1997:285)-, los que analizan el rol de los movimientos sociales, los que abordan la relación entre estructura de clase y democracia, los que aplican un análisis desde la economía política y los que se centran en el análisis geopolíticos e internacionales (Ackerman, 2006, p. 118).

Desde la visión de los procesos políticos, y largamente dedicado a comprender las transiciones hacia el autoritarismo burocrático y desde las dictaduras hacia las democracias, Guillermo O'Donnell, en conjunto con Phillipe Schmitter (O’Donnell \& Schmitter, 1984) buscará comprender las etapas por las cuales atraviesan las transiciones que ponen fin a las dictaduras, avanzando desde la etapa de liberalización, hasta períodos de democracia más sustantiva.

En este sentido, la primera etapa de liberalización que definen estos autores, se centraría justamente en recuperar las libertades individuales clásicas “de la tradición liberal” (O’Donnell \& Schmitter, 1984, p. 20) y en las grupales asociadas a la libertad de expresión, la ausencia de censura a los medios de comunicación y la libertad de asociación. Desde aquí se haría necesario el avance hacia la democratización, que es definida por estos autores como "el derecho de ser tratado por otros seres humanos como igual con respecto a la formulación de opciones colectivas, como la obligación de quienes instrumentan dichas opciones de ser accesibles y responder por igual frente a todos los miembros del sistema político" (O’Donnell \& Schmitter, 1984, p. 21). Una tercera etapa, finalmente, sería la de socialización, en la cual se consolidan ciertos elementos de igualdad sustantiva al interior del sistema democrático. (O’Donnell \& Schmitter, 1984,p.28),que unifica lo que los autores entienden como democracia social y democracia económica (O’Donnell \& Schmitter, 1984,p. 28) y que, aquí entendemos como un elemento más de la democratización.

Por otro lado, el análisis de O’Donnell y Schmitter incorpora una visión sobre el conflicto, el que -desde su perspectiva- estaría ausente en los periodos de transición exitosa. De este modo, avizoran la posibilidad de presión democratizadora, pero de manera posterior al inicio de la transición, asociándola con una "resurrección de la sociedad civil" (O’Donnell \& Schmitter, 1984, p. 81), lo que en la práctica -desde nuestra perspectivadaría cuenta de la importancia de la movilización social como fórmula para avanzar hacia mayores niveles de democracia. Desde esta perspectiva no 
tan evidente, las transiciones sin conflicto no resultarían tanto exitosas, como sí buenas formas de opacar el conflicto, el que no resuelven sino que delegarían hacia etapas posteriores. En este sentido, es posible sostener que la moderación y la renuncia a ciertas demandas en períodos de transición, -contradictoriamente destacada por estos autores como una señal de éxito- no sería más que justamente eso: “transitoria”, debiendo por ende, considerarse períodos más largos de análisis para evaluar los supuestos éxitos de las transiciones, así como la reaparición de las demandas democratizadoras "interrumpidas” por los períodos autoritarios y amilanadas en los períodos de transición.

Por otro lado, algunos de los aspectos más criticados de las premisas establecidas por O’Donnell y Schmitter se asocia a la importancia que le otorgan a las élites y a la moderación de los sectores más radicales en períodos de transición, cuestión que ha sido marcadamente predominante en análisis que se han realizado en Chile sobre el inicio de la transición en este país (Garretón, 1987). De este modo, algunos estudios posteriores al de O’Donnell y Schmitter han intentado encontrar nuevos elementos que permitan relativizar esta primera visión ${ }^{6}$.

Finalmente, superando el análisis sobre "nuevos movimientos sociales” una de las teorías más reconocidas que sobre "contienda política”, es la seguida por Charles Tilly. Tilly, quién inicia su análisis desde la sociología histórica, introduciendo el conflicto en dicha perspectiva, aporta más tarde al desarrollo de la teoría de movimientos sociales en conjunto con los sociólogos estadounidenses Dough McAdams y Sidney Tarrow. De este modo, Tilly logra abordar tanto las revoluciones, los movimientos sociales, las “democratizaciones” y los nacionalismos-, para establecer una mirada reflexiva sobre los "mecanismos y procesos similares" y "secuencias causales” (Tilly, Tarrow, \& McAdams, 2005:14) que trae aparejados estos tipos de “contienda”.

Más tarde, en conjunto con McAdams y Tarrow, Tilly avanzará hacia un análisis complejo de la contienda política y la movilización social, aplicando un "enfoque relacional” (Tilly, 2007, p. 25; Tilly, Tarrow, \& McAdams, 2005, p. 6). Por esta vía, los autores buscarán superar las falencias que suponen otros enfoques sobre movimientos sociales, a medida que desarrollan una metodología que no se plantea desde una lógica esencialista y que aporta con una mirada integral de los procesos, en los que se consideran no solo los intereses de los grupos que entran en conflicto, sino también las estrategias del momento y las alianzas que se forman, las identidades que se crean y se modifican y otros “mecanismos" diversos (Tilly et al., 2005, p. 250).

El análisis sobre movimientos sociales, no obstante, limita en algunas ocasiones, la mirada histórica, el análisis de las ideas y, como consecuencia también, la comprensión sobre el concepto de democracia y los niveles de democratización. Un ejemplo, en este sentido, lo entrega la investigadora Donatella Della Porta quien, partiendo de una breve revisión 
histórica, liga las prácticas democráticas renovadas por los movimientos sociales de los últimos años con las que dieron "origen” a la democracia. Incorporando nuevamente el ejemplo de las prácticas democráticas clásicas como punto de partida, Della Porta sitúa en el movimiento de trabajadores emergente con la Revolución Francesa la aparición de las distintas formas o prácticas democráticas que recuperan los movimientos sociales en la actualidad. Entre estas prácticas se encontrarían la horizontal, la autogestionada y la directa (Della Porta, 2013, p. 50) ${ }^{7}$. Aun así, sí asocia al movimiento de trabajadores la permanente lucha por la transformación de la democracia liberal en una que contemple tanto los derechos civiles y políticos como sociales (Della Porta, 2013, p. 51).

De este modo, Della Porta ahonda en las nuevas y renovadas prácticas democráticas que han surgido gracias a la acción y presión de movimientos sociales en el período posterior a la década del '70 y ' 80 , las que estarían orientadas a equilibrar el poder que en la actualidad han adquirido las grandes multinacionales y organizaciones internacionales financieras, por encima de los Estados y sobre todo por encima de los ciudadanos. Estas prácticas serían una forma de "salvar la democracia” y recuperar su contenido de igualdad, asociada a factores más esenciales que la mera participación electoral (Della Porta, 2013, p. 39).

En este sentido, la “democracia participativa” rescatada por Della Porta, sería una forma de recuperar "lo político" para la ciudadanía, generando mayor compromiso e igualando a la primera en cuanto a posibilidad de incidir. La democracia participativa, además, tendría también cualidades respecto de considerar las diferencias entre los participantes ${ }^{8}$. La cercanía a la toma de decisiones por parte de la población, colaboraría, por otro lado, en generar opiniones informadas, más allá de las mostradas de manera efectista por las encuestas y los medios de comunicación.

Lo mismo se puede decir de otra noción sobre democracia que aborda Della Porta, ésta es la de "democracia deliberativa”. Esta definición se centra en cómo los ciudadanos toman decisiones en conjunto, pero abiertos a razonar y sopesar las opiniones de los otros como forma de modificar su propia opinión. Basada en parte en la teoría de la acción comunicativa y en la de opinión pública de Habermas (Della Porta, 2013:10), la noción de democracia deliberativa o consensual se liga también con los movimientos sociales surgidos en las últimas décadas, entre ellos los Foros Sociales Mundiales y las movilizaciones y ocupaciones ocurridas en distintos lugares del mundo en contra del modelo económico globalizado. (Della Porta, 2013, p. 67).

No obstante, el análisis de Della Porta no aborda el cómo se generan las condiciones necesarias para sostener la igualdad u horizontalidad que requiere la toma de decisiones. De este modo, dicha visión mantiene la definición sobre democracia en el ámbito de los procedimientos, sin ahondar en cómo la estructura social influye en la capacidad y posibilidad de influir en los mismos. En este sentido, el análisis mantiene una visión inge- 
nua sobre el conflicto político, dado que no toma en cuenta sus posibilidades de aplicación cuando se juegan grandes intereses o visiones ideológicas radicalmente opuestas. Si bien, limitar el conflicto político entendido como amigo-enemigo, reconociendo una práctica “agonística” de la política -aparece a todas luces necesario- abstraer dicha práctica de las condiciones materiales que requeriría la democracia a nivel institucional para resolver realmente los conflictos sociales, redunda en una mirada limitada del conflicto democratizador y de la propia concepción sobre democracia.

En conclusión, hasta aquí los análisis sobre el conflicto democratizador nos permiten reconocer una serie de enseñanzas. Entre estas se encuentran el hecho de que muchos estudios presuponen lo que se entiende por democracia, asociando el término sin mayor análisis al proyecto político burgués durante la Revolución Francesa, el cual en sí mismo nunca abogó por la participación del demos. Creemos que la no comprensión sustantiva del esquema de fuerzas que se incorporan en el conflicto político, así como de la dinámica del conflicto y la limitación de la perspectiva histórica impide comprender el conjunto de las demandas y los intereses que establecen los conflictos democratizadores. En este sentido, esto implica no considerar el contenido moral y relacional de las demandas planteadas, sino, solamente la institucionalización de un proceso.

Al mismo tiempo, la limitante histórica, impide asociar a la demanda democrática, participativa, deliberativa y horizontal, el contenido de igualdad material que requiere la demanda democratizadora, el que no puede quedar solo a nivel “expresivo” para ser sustantiva.

En este sentido, el aporte de Tilly et. al, pero también de Rustow hacia un análisis metodológico dinámico o “circular”, apunta nuevamente a revisar los conflictos políticos en toda su complejidad, incluyéndolos en una comprensión histórica, pero también -desde nuestra perspectiva- en una discusión moral sobre democracia.

El análisis histórico, por último, también implica la consideración del contexto internacional, el que, como destaca Therborn, también resalta la diversidad de escenarios que puede enfrentar un conflicto democratizador. Desde esta perspectiva, las demandas por mayor democracia de los últimos años, entre las que podemos incluir el movimiento 15M en España, el movimiento estudiantil en Chile, el movimiento feminista y otros en América Latina, no pueden obviar el contexto de apertura económica mundial que las últimas décadas ha tendido a limitar las capacidades de incidencia del Estado-nación en la política pública y social, tendiendo más bien hacia la igualación por debajo de los sistemas de seguridad social y a la desregulación laboral, limitando al mismo tiempo las áreas de incidencia de los gobiernos electos. En este sentido, la democratización aparece como consecuencia no siempre única- del conflicto, poniendo en evidencia la necesidad del quiebre epistemológico y en el sentido común que lleva a la transformación del orden, así como la consideración, desde el análisis social, de cuáles son las demandas planteadas y cuáles son los niveles y contenidos de la demo- 
cratización que los agentes/clases/movimientos buscan alcanzar. Este parámetro permitirá evaluar la profundidad histórica de la demanda, comparándola también con otros períodos y con los propios acuerdos -muchas veces tácitos- establecidos por distintos sectores sociales.

Por último, la redefinición de los límites del Estado-nación que puede traer consigo la política tipo Trump-brexit, nos debe llevar también a reflexionar de qué manera puede esto redefinir la fortaleza, el contenido y las fronteras de los actuales movimientos democratizadores.

\section{La Democratización como movimiento histórico}

Como veíamos en el apartado anterior, difícilmente se puede hablar de democratización sin una concepción clara y una asunción normativa, así como material e históricamente fundada, sobre lo que se entiende por democracia. Bajo la noción de modernidad política buscaremos entonces retomar un análisis que rearticule el componente normativo sobre democracia, con el análisis histórico y las condiciones materiales que hacen posible evaluar la extensión misma de la democracia, lo que, desde nuestra perspectiva restablece un vínculo con la tradición republicano-democrática, es decir, la tradición que reconoce que la incorporación a la polis requiere de medios de sobrevivencia para establecer relaciones en un plano de igualdad y libertad (Domenèch, 2003). Por otro lado, la referencia a la materialidad busca establecer también una definición de democracia que reconozca la dependencia que establece "lo político" de las relaciones entre el ser humano con otros seres humanos, y de estos con su entorno físico y social, entendiendo que éste último determina la "forma" que toma la demanda democratizadora para cada período histórico.

En este sentido, nos distanciamos de una idea de autonomía asociada al pensamiento económico neoclásico (Domenèch, 2010, p. 33) ${ }^{9}$, que la entiende como libertad de la propia economía -como ley ajena a lo social ${ }^{10}$ , así como del individuo como agente únicamente económico o maximizador de ganancia. Es este concepto de autonomía ligado al pensamiento liberal, el que es característico y va aparejado al surgimiento del capitalismo (Casassas, 2010) y no es definitorio, por tanto del concepto de democracia.

La noción de modernidad política que trabajamos aquí no disocia, por ende, la idea de libertad o autonomía individual de los medios físicos o materiales necesarios para que ésta sea posible, y remite por tanto a situar la noción de autonomía en un contexto de relaciones de poder y de distribución de la riqueza, aparejados a una institucionalidad específica, donde se articulan el problema "formal” de la persona jurídicamente libre (...) del problema, (...) de las bases institucionales y materiales en que se as[ienta] su libertad, su autonomía y su “virtud” como "persona” (Domenèch, 2003, p. 42).

Por este camino analítico avanzan también los aportes de Axel Honneth y E.P. Thompson; el primero buscando reconocer el componente 
“moral” que a nivel individual -personal o de amor propio (Casassas, 2010)e identitario presenta el conflicto social o lo que según su definición, serían "las reglas implícitas [o expectativas] de reconocimiento recíproco” (Honneth, 1997:193). Mientras tanto, E.P. Thompson se enfoca en la “economía moral de la multitud”, -análisis que rechaza de manera tajante la simplificación del conflicto de clases realizada por ciertos marxismos (Callinicos, 2009; Thompson, 1981)- incorporando variables relacionales y asociadas a las creencias, esquema de fuerzas y contexto histórico en que las clases se forman (Gauthier, 2013; Thompson, 1966).

Ambos autores se enfocan así en comprender el rol de los conflictos y de los movimientos sociales desde una perspectiva democratizadora, aportando el primero desde una noción de autonomía generada intersubjetivamente que hace posible el desarrollo personal e identitario y que remite a las necesarias condiciones materiales y de reconocimiento que deben existir socialmente para que alcanzar dicha autonomía, mientras el segundo da cuenta de los acuerdos implícitos establecidos entre clases, los que refuerzan una noción de bien común colectivamente acordado, la que genera identidades a largo plazo.

Desde la perspectiva Thompson entonces, el conflicto democratizador -sin que esto pueda convertirse en un esquema causalsobrevendría cuando un sector de la sociedad o clase se siente explotado o despojado de ciertos beneficios o costumbres tradicionales, despojo contra los que se resiste. En este sentido, el conflicto surgiría cuando un sector siente que algo que es considerado justo, en base a la tradición y el acuerdo colectivamente generado sobre el bien común, ha sido afectado por algún cambio, lo que provoca la manifestación y movilización. De este modo, tomando en consideración el aporte de Thompson, se debe rescatar que, para evaluar un conflicto democratizador es preciso revisarlo en un contexto histórico de referencia(Wagner \& Rosich, 2015, p. 271), así como en un marco de acuerdo colectivamente fundado como "economía moral de la multitud” o de clase, como construcción “material” e histórica (Thompson, 1984, p.34) ${ }^{11}$.

No obstante, el análisis de Thompson, orientado a analizar el conflicto de clases, no aborda los conflictos asociados a una búsqueda de autonomía como ruptura con la tradición hegemónica y que se asocia a las necesidades de reconocimiento de colectivos con características no asociadas directamente a la relación productiva o material, sino más específicamente de dominación. La democratización de este modo, no pasa solo por la extensión de los beneficios colectivos, sino también a la posibilidad de que los individuos y grupos con identidades adscriptivas puedan incorporarse en condiciones de no dominación -de reconocimiento- a la sociedad.

En este sentido, el análisis de Axel Honneth respecto del reconocimiento, nos permite considerar los aspectos subjetivos e intersubjetivos que orientan el conflicto colectivo e individual desde las identidades, $\mathrm{y}$ 
avanzan también hacia la democratización de posibilidades de desarrollo individual y social. El filósofo y sociólogo alemán ahonda, al igual que lo hace Thompson, en entender el conflicto desde una perspectiva no mecánica ni estructural, sino radicada en un contexto de relaciones sociales, así como de necesidades individuales y de colectivos que se encuentran en una posición de dominación, situación que genera una identidad específica. Fundamentando su teoría en el psicoanálisis, en el interaccionismo simbólico y en la filosofía Hegeliana, Honneth actualiza el análisis de Hegel respecto del reconocimiento como forma de establecer la propia autonomía (Honneth, 1997, p. 88), ya que -según indica- Hegel deja de lado este análisis, para finalmente centrarse en la conformación de un Espíritu como razón universal $^{12}$.

Honneth intenta, a partir de esto, establecer un modelo de eticidad que permita la determinación de "un horizonte abstracto de valores éticos que esté abierto a los diferentes objetivos de vida” (Honneth, 1997, p. 215) -sin que con ello se pierda la identificación colectiva-, mientras que asocia a la sociedad moderna y sus luchas la necesidad de ampliar radicalmente las relaciones de solidaridad ${ }^{13}$. De esta manera, Honneth atribuye al análisis sobre la lucha por el reconocimiento la "corrección” del modelo utilitarista de intereses, entendido como el "intento de grupos sociales por conservar su poder de decisión sobre determinadas oportunidades de reproducción o incrementarlo" (Honneth, 1997, p. 199).

En este ámbito, el propio Honneth destaca el aporte que el historiador E.P. Thompson ha realizado en términos de comprender el conflicto dentro de un marco más complejo de relaciones y luchas sociales (Honneth, 1997, p.200) y también de Barrington Moore, al que liga a Thompson a través del concepto de “contrato social implícito” (Honneth, 1997, p.202). El aporte de Honneth consiste entonces en dar cuenta de que existen personas que interactúan entre sí y que para desarrollarse en todas sus capacidades deben situarse en un contexto en el que no sólo cuenten con un sustento que haga real su independencia para poder ser libres, sino también que potencie el amor, el autorespeto y la autoestima para poder lograr la autonomía de su propia personalidad.

En conclusión, tanto el análisis de Honneth como el de Thompson aportan con una visión sobre las relaciones sociales que da cuenta de su construcción dinámica e intersubjetiva y de su configuración en un contexto de dominación o de articulación de fuerzas. En este sentido, se alejan de una comprensión estática, abstracta y netamente liberal del conflicto. Reconocen, de este modo, el conflicto asociado a la cultura o a la "moral", la que genera identidades, conflictos internos o subjetivos, demandas, sensaciones de malestar, acuerdos sobre el bien común, pero también luchas por el reconocimiento de los acuerdos comunes y de las identidades subjetivas. En este sentido, la investigación histórica y sociológica y el estudio de las demandas en su contexto, en su inter y subjetividad nutre al análisis con interpretaciones más afincadas en la evaluación de los propios actores y no en conceptos distorsionados por la distancia histórica. 
Por último, tanto Honneth como Thompson entregan una aproximación empírica flexible y cualitativa, que si bien no claramente estructurada, permite contemplar aspectos de importancia respecto del desarrollo del conflicto democratizador y el fundamento de las demandas que los colectivos, clases e individuos realizan, aportando para reevaluar con mayor profundidad y con un enfoque en "procesos" la configuración identitaria y el contenido de justicia, reconocimiento y autonomía material, personal y colectiva que impulsan los conflictos hacia mayor democracia.

\section{Conclusión}

Una de las grandes amenazas de la democracia en la actualidad y durante las últimas décadas, ha sido entenderla como un modelo estático, como un sistema que requiere precondiciones, como propia de un período en específico, como unívocamente relacionada con el capitalismo -y no como una práctica distinta decisionaria horizontal e inclusiva- o como un proceso que nada tiene que ver con la identidad, en el cual los intereses se definen según la estructura económica o la "acción comunicativa”, loque bastaría para llegar a un acuerdo sobre elementos que pasan por el reconocimiento de lo subalterno; la amenaza ha sido también creer que ésta funciona de manera mecánica y no surge como "consecuencia del proceso histórico" de ganancias y pérdidas, donde el futuro no es siempre progresista y el pasado no siempre implica reacción.

El cierre epistemológico que ha implicado la asociación directa entre autonomía individual y deseo egoísta, así como la asimilación del ser humano a un homos economicus, es también una amenaza tanto para la democracia, como para la ciencia social y para el análisis que intenta interpretar el cambio social en toda su complejidad y riqueza histórica.

En este texto, se ha intentado por lo tanto, reconfigurar un concepto de democracia anclado históricamente, a la vez que entender dicho concepto como "recuperado" durante los procesos de conflicto democratizador y por las definiciones de fuerza que estos conflictos establecen entre diferentes colectivos.

Como conclusión, se ha intentado reconocer en el concepto de "modernidad política”, la posibilidad de abarcar los procesos de democratización en toda su complejidad, incluyendo con ello elementos de reconocimiento intersubjetivo, así como de acuerdo implícito colectivo, en los que radica una "economía moral de la multitud" y el desarrollo de la propia identidad. 


\section{Notas}

${ }^{1}$ Este artículo forma parte de la tesis doctoral Democracia, Conflicto y Democratización en la historia de Chile, el cual se realizó como parte del Proyecto liderado por el Dr. Peter Wagner, Trajectories of Modernity (EuropeanResearch CouncilAvancedGrant) del Centro de Estudios sobre Cultura, Política y Sociedad (CECUPS)Universidad de Barcelona (www.ub.edu/tramod).

${ }^{2}$ Para el sociólogo Randall Collins dicho análisis no pasará de ser una visión superficial comprobada por la sola experiencia personal (Collins, 1996, p. 121)

${ }^{3}$ Otros pensadores como Theodor Adorno, Herbert Marcuse, así como Hanna Arendt se avocarán a entender más bien cuáles son las causas para la aparición del fascismo y el anti-semitismo.

${ }^{4}$ Manteniendo una visión sobre democracia en su sentido liberal, Moore indica que el empuje radical de la Revolución Francesa fue inicialmente intensamente anticapitalista (Moore, 2002, p. 115), esto es, en rechazo de la propiedad privada, de la libertad de precios que llevaba a la especulación y en favor de las tierras comunes, empuje que se habría opuesto a la burguesía y los "derechos del hombre". Sin embargo, finalmente los sectores burgueses habrían logrado instalar un sistema económico basado en la propiedad privada y la igualdad ante la ley, así como la democracia parlamentaria (Moore, 2002,p. 166). Moore no obstante, no realiza un análisis desde las ideas políticas que se ponen en práctica con cada transformación, sino desde el interés económico que propician los diferentes grupos, donde asimila, sin mayor análisis, la propiedad privada a la libertad y el radicalismo (anticapitalismo) a la tradición, a pesar de lo cual reconoce tanto en el fascismo, la revolución burguesa y la revolución comunista, formas de resolver el problema económico planteado por la expansión del capitalismo (Moore, 2002, p. 586).

${ }^{5}$ Es decir, aquella en la que el Estado tiene una composición de clase burguesa y en la que opera para mantener y promover las relaciones capitalistas de producción y el carácter clasista del aparato estatal (Therborn, 1977b:4).

${ }^{6}$ Un ejemplo es Elizabeth Jean Wood, analiza lo que ella denomina "insurgentpath to democracy” (Wood, 2001, p.863). Wood indica que en estos procesos las élites se ven presionadas, además de obligadas a la democratización por efecto de la movilización de sectores excluidos ("from below"), que afecta y daña el mapa de intereses económicos de las propias élites. Una conclusión similar es alcanzada por Eva Bellin, a través de establecer la gama de motivaciones que se correlacionan con el apoyo que, tanto la clase empresarial como la trabajadora en la actualidad darían a un proceso de democratización.

Por último, en la discusión respecto de las élites y su peso en los procesos de democratización/transición, Ruth Collier y James Mahoney(Collier \& Mahoney, 1997), a través del análisis de las transiciones de la década del '80 en Sud-América y Europa del Sur, buscan mostrar cómo las transiciones desde las dictaduras han sido influidas por la presión ejercida por parte de las clases trabajadoras, lo que sucede incluso en España que ha sido el caso paradigmático en cuanto a la importancia de las élites en el proceso de democratización. Lo mismo indica el análisis de Nancy Bermeo, que establece que los niveles que alcanza la democratización post-autoritaria tampoco son, por regla limitados y moderados (Bermeo, 1999). 
${ }^{7}$ De este modo, Della Porta define primero la ya mencionada “concepción hegemónica de la democracia" (Santos, 2004, p. 45) o democracia liberal, que entiende como aquella centrada en la convocatoria a elecciones “competitivas, justas y recurrentes", que tiene además una concepción de representatividad democrática (Della Porta, 2013, p. 14). La responsabilidad sobre la política, en este tipo de democracia, se sitúa en los representantes y sobre áreas limitadas de transformación. En esta línea, la autora, siguiendo la visión de Robert Dahl, la define como "the continuing responsiveness of the government to the preferences of its citizens, considered as political equals" (Della Porta, 2013:13), así como la posibilidad de expresar preferencias, manifestarlas individual y colectivamente y que éstas "pesen lo mismo en el conducto hacia el gobierno, es decir, sean sopesadas sin discriminación en cuanto al contenido o fuente de la preferencia” (Della Porta, 2013, p. 13, traducción propia). Por su parte, la democracia se concibe como una competencia entre individuos para la resolución pacífica de tensiones, mientras los conflictos entre colectivos se consideran patológicos (Della Porta, 201, p.15)

${ }^{8}$ Para Boanaventura Do Sousa Santos y Leonardo Avritzer, por otro lado, esta virtud de la democracia participativa se relaciona con el poder acercar el ámbito decisional a un espacio en el cual las diferencias e identidades pueden expresarse (Santos, 2004, p. 67).

${ }^{9}$ De este modo, según señala Antoni Domènech, -pero también Hirschman (A. O. Hirschman, 1991) y Huntington (Huntington, 1994), si bien la visión "liberal” sobre democracia y política es el pensamiento que termina predominando, asociado a la Escuela Económica Clásica, en la práctica éste se basa en una concepción errada y falseada sobre la concepción ilustrada de la propiedad anterior a esta Escuela, donde Locke, basándose en sus conocimientos de derecho romano, considera la propiedad privada como una cesión temporal fiduciaria de parte del pueblo tanto al parlamento (en lo que refiere al cargo político), como a los que acceden a la propiedad, siempre y en tanto que el primero mantenga la confianza en el bueno uso de los segundos (Domenèch, 2003).

${ }^{10}$ Lo que la historiadora Florence Gauthier tilda como una forma de teología (2013:420) y el economista Albert O. Hirschman menciona como "intervención mágica de la Divina Providencia” (A. O. Hirschman, 1991, p. 16)-

${ }^{11}$ Para Thompson el concepto de "Clase (...) es una categoría histórica; es decir, está derivada de la observación del proceso social a lo largo del tiempo. Sabemos que hay clases porque las gentes se han comportado repetidamente de modo clasista; estas sucesos históricos descubren regularidades en las respuestas a situaciones similares, y en un momento dado (la formación «madura" de la clase) observamos 'la creación de instituciones y de una cultura con notaciones de clase que admiten comparaciones transnacionales” (Thompson, 1984, p. 34).

${ }^{12}$ Para Honneth sería G.H. Mead quien continúa la tarea de Hegel a través del análisis sobre la constitución intersubjetiva del yo, lo que Honneth califica como una versión “materialista” del análisis de Hegel (Honneth, 1997, p. 115). Más tarde, afirmándose en el psicoanálisis como una forma primaria de reconocimiento, que permite la constitución autónoma de la persona y una relación de confianza con su entorno, Honneth ahonda en el reconocimiento como derecho individual extendido a todos los miembros 
de una sociedad, lo que hace que cada uno pueda reconocerse a sí mismo en el autorespeto y en el reconocimiento que otros hacen de uno mismo. Las relaciones simétricas (es decir, en la que cada sujeto se siente valorado) entre individuos autónomos, generarían para Honneth una relación de solidaridad o valoración social (Honneth, 1997, p. 159) de la que derivarían tres formas de reconocimiento que definen la autoconfianza (ligada al amor), el autorespeto (ligada al reconocimiento jurídico) y el autoestima (ligado a las experiencias de solidaridad), los que "constituyen los preparativos intersubjetivos de protección de aquellas condiciones que aseguran la libertad interior y exterior” (Honneth, 1997, p. 210).

${ }^{13}$ Honneth plantea así un avance normativo progresivo dirigido hacia establecer tres formas de reconocimiento, en las que el individuo puede conseguir respeto por la propia particularidad individual y que incide en la posibilidad de reconocerse en la colectividad (Honneth, 1997, p.43). En este sentido, Honneth ahonda en una cierta posibilidad de "desarrollo global” del reconocimiento, debiendo establecerse una "medida normativa” para distinguir "los motivos progresistas y los regresivos” (Honneth, 1997, p. 203). 


\section{Bibliografía}

Ackerman, J. M. (2006). Democratización: pasado, presente y futuro. Perfiles Latinoamericanos, 14(28), 117-157.

Aguilar, O. (2005). Sociología y modernización. Revista Némesis, (5), 131150, Recuperado de file://C:/Users/Gabriela/Downloads/ descargar\%20revista\%20nemesis\%20n5.pdf

Bermeo, N. (1999). TheMyths of Moderation: The Role of Radical Forces in theTransition to Democracy. In Anderson, L. (Ed.), Transitions to Democracy (pp. 120-140). New York, U.S.A.: Columbia UniversityPress.

Callinicos, A. (2009). MakingHistory: Agency, Structure, and Change in Social Theory. Oxford, UK: Haymarketbooks.

Casassas, D. (2010). La Ciudad en Llamas: La Vigencia del Republicanismo de Adam Smith. Madrid, España: Montecinos.

Collier, R. B., \&Mahoney, J. (1997). AddingCollectiveActors to CollectiveOutcomes: Labor and RecentDemocratization in South America and SouthernEurope. ComparativePolitics, 29(3), 285303.

Collins, R. (1996). Cuatro Tradiciones Sociológicas. Iztapalapa, México: Universidad Autoìnoma Metropolitana Unidad Iztapalapa.

Dahl, R. A. (1992). La Democracia y sus Críticos. Barceloa, España: Paidós.

Dahrendorf, R. (1958). Toward a Theory of Social Conflict. TheJournal of ConflictResolution. 2(2), 170-183.

Dahrendorf, R. (1966). Sociedad y Libertad. Madrid, España: Tecnos.

Della Porta, D. (2013). Can democracy be saved??: participation, deliberation and social movements. PolityPress.

Domenèch, A. (2003). El Eclipse de la Fraternidad: Una visión republicada de la tradición socialista. Barcelona, España: Critica.

Domenèch, A. (2010). La Ciudad en Llamas: La Vigencia del Republicanismo de Adam Smith. In La Ciudad en Llamas: La Vigencia del Republicanismo de Adam Smith. Madrid, España: Montecinos.

Dubiel, H. (1998). CultivatedConflicts. PoliticalTheory, 26(2), 209-220.

Garretón, M. A. (1987). Las complejidades de la transición invisible: movilizaciones populares y régimen militar en Chile. Revista Propo- 
siciones, 14, 113 -131. Recuperado de http://www.sitiosur.cl/ r.php?id=667

Gauthier, F. (2007). De Juan de Mariana a la Marianne de la República Francesa o el escándalo de resistir a la opresion. Sin Permiso, (2).

Gauthier, F. (2013). De la “economía moral” a la “economía política popular”: la fructífera intuicion de Edward P. Thompson. Sociología Histórica, (3), 397-426.

Hegel, G. W. F. (2003). Fenomenología del Espíritu. México, D.F., México: Fondo de Cultura Econoìmica.

Hirschman, A. (1994). Social Conflict as Pillars of DemocraticMarketSociety. PoliticalTheory, 22(2), 203-218.

Hirschman, A. O. (1991). TheRhetoric of Reaction. Harvard, UnitedStates: Harvard College.

Honneth, A. (1997). La Lucha por el reconocimiento?: por una gramática moral de los conflictos sociales. Barcelona, España: Crítica.

Huntington, S.(1994). La Tercera Ola, la democratización a finales del siglo $X X$. Buenos Aires, Argentina: Paidos.

Moore, B. (2002). Los Orígenes Sociales de la Dictadura y de la Democracia: El señor y el campesino en la formación del mundo moderno. Barcelona, España: Península.

O’Donnell, G., y Schmitter, P. (1984). Transiciones desde un Gobierno Autoritario: Conclusiones tentativas sobre las democracias inciertas. Buenos Aires, Argentina: Paidós.

Rustow, D. A. (1970). Transitions to Democracy: Toward a DynamicModel. ComparativePolitics, 2(3), 285-303.

Santos, B. de S. (Coord). (2004). Democratizar la democracia?: los caminos de la democracia participativa. Madrid, España: Fondo de Cultura Econoìmica.

Serrano, E. (1997). El Conflicto Político: Una reflexión filosófica. Medellín, Colombia: Universidad de Antioquía.

Smelser, N. (1995). Teoriìa del comportamiento colectivo. Meìxico D.F, México : Fondo de Cultura Econoìmica.

Therborn, G. (1977a). The Rule of Capital and theRise of Democracy. New LeftReview, (103), 3-41. 
Thompson, E. P. (1966). TheMaking of the English WorkingClass. Nueva York, UnitedStates: VintageBooks.

Thompson, E. P. (1981). Misería de la Teoría. Barcelona, España: Crítica.

Thompson, E. P. (1984). Tradicion, Revuelta y Conciencia de Clase, estudios sobre la crisis de la sociedad preindustrial. Barcelona, España: Crítica.

Tilly, C. (1991). Grandes estructuras, procesos amplios, comparaciones enormes. Madrid, España: Alianza Editorial.

Tilly, C. (2007). Violencia Colectiva. Barcelona, España: Hacer editorial.

Tilly, C., Tarrow, S., y McAdams, D. (2005). Dinámica de la Contienda Política. Barcelona, España: Hacer editorial.

Velasco, A. (2002). El Concepto de la Sociedad Civil: una visión históricofilosófica. En Salazar, R. (coord) Comportamiento de la Sociedad Civil Latinoamericana. Sinaloa, México: Universidad Autónoma de Sinaloa.

Wagner, P. (1995). A Sociology of Modernity, Liberty and Discipline. The British Journal of Sociology, 46

Wagner, P. (2001). A history and Theory of the Social Sciences. London, ThousandOaks, New Delhi: Sagepublications.

Wagner, P., \&Rosich, G. (2015). Democracy as CapacityforSelfTransformation. In P. Wagner \& G. Rosich (Eds.), TheTroublewithDemocracy, politicalmodernity in the 21th century. Edinburgh, Inglaterra: Edinburgh UniversityPress.

Wood, E. J. (2001). AnInsurgentPath to Democracy: Popular Mobilization, EconomicInterests, and RegimeTransition in South Africa and El Salvador. ComparativePoliticalStudies, 34(8), 862-888.

Recibido: 15.03 .17

Aceptado 15.04.17 